WP 16_12

\author{
Thanasis Stengos \\ University of Guelph, Canada \\ The Rimini Centre for Economic Analysis (RCEA), Italy \\ M. Ege Yazgan \\ Istanbul Bilgi University, Turkey \\ The Rimini Centre for Economic Analysis (RCEA), Italy
}

\title{
Persistence in Real Exchange Rate CONVERGENCE
}

Copyright belongs to the author. Small sections of the text, not exceeding three paragraphs, can be used provided proper acknowledgement is given.

The Rimini Centre for Economic Analysis (RCEA) was established in March 2007. RCEA is a private, nonprofit organization dedicated to independent research in Applied and Theoretical Economics and related fields. RCEA organizes seminars and workshops, sponsors a general interest journal The Review of Economic Analysis, and organizes a biennial conference: The Rimini Conference in Economics and Finance (RCEF) . The RCEA has a Canadian branch: The Rimini Centre for Economic Analysis in Canada (RCEACanada). Scientific work contributed by the RCEA Scholars is published in the RCEA Working Papers and Professional Report series.

The views expressed in this paper are those of the authors. No responsibility for them should be attributed to the Rimini Centre for Economic Analysis. 


\title{
Persistence in Real Exchange Rate Convergence
}

\author{
Thanasis Stengos \\ University of Guelph (tstengos@uoguelph.ca) \\ M. Ege Yazgan * \\ Istanbul Bilgi University (eyazgan@bilgi.edu.tr)
}

April 19, 2012

\begin{abstract}
In this paper we use a long memory framework to examine the validity of the Purchasing Power Parity (PPP) hypothesis using both monthly and quarterly data for a panel of 47 countries over a fifty year period (1957 to 2009). The analysis focusses on the long memory parameter $d$ that allows us to obtain different convergence classifications depending on its value. Our analysis allows for the presence of smooth structural breaks and it does not rely on the use of a benchmark. Overall the evidence strongly points to the presence of a long memory process, where $0.5 \leq d<1$. The implication of our results is that we find long memory mean reverting convergence, something that is also consistent with Pesaran et al (2009). In explaining the speed of convergence as captured by the estimated long memory parameter $d$ we find impediments to trade such as distance between neighboring countries and sticky prices to be mainly responsible for the slow adjustment of real exchange rates to PPP rather than nominal rates for all country groups but Asia, where the opposite is true.
\end{abstract}

JEL Classification: C23, E31, F41.

Keywords: Purchasing Power Parity, Convergence, Long Memory, Pairwise Approach.

${ }^{*}$ We would like to thank an anonymous referee for very useful comments that helped improve the substance and personation of the paper. We would like to also thank seminar participants of Koc University and the 5th Annual Methods in International Finance Network Workshop. 


\section{Introduction}

Purchasing power parity (PPP) has been subjected to countless empirical investigations as it constitutes the central working hypothesis in many macro economic models. Since, at the aggregate level, PPP implies that the nominal exchange rate should converge to the ratio of price levels between two countries, we expect the real exchange rate to be a mean-reverting process. Hence, the bulk of this empirical research has manifested itself as testing price-level convergence across countries; i.e., testing the stationarity of aggregate real exchange rates ${ }^{1}$.

In one of the most comprehensive surveys of the subject Taylor and Taylor (2004, p.153) stated that "while the empirical work could only find the flimsiest evidence in support of PPP, and even these weak findings implied an extremely slow rate of reversion to PPP of, at best, three to five years". Based on the results of new panel data studies, which are supposed to have more power than results based on individual unit root tests (see Levin et al. (2002)), this statement is rephrased in a less pessimistic manner by Crucini and Shintani (2008, p.629) as "After decades of scrutiny, the consensus is that aggregate real exchange rates are stationary, but very persistent with estimated half-lives in the range of 3-5 years" (see Choi et al. (2006), Murray and Papell (2005), Frankel and Rose (1996)).

This slow convergence, or high persistence in real exchange rates, has attracted a lot of attention in the literature since it is hard to rationalize on the basis of monetary factors and it offers an additional argument against the validity of PPP. One of the major insights of Gustave Cassel, when he posited PPP in 1922 as a theory of exchange rate movements, was that PPP only holds if the sources of price disturbances are monetary in nature This can be easily seen from the fact that PPP theory predicts that, when a monetary shock occurs, say, as an increase in the money supply, that will increase both domestic prices and the nominal exchange rate in the same proportion in the long-run. Therefore, an increase in the money stock will cause a reduction in the purchasing power of money in terms of both currencies when all the adjustments are completed. In this sense, PPP theory can be thought of as an open economy version of the quantity theory of money. This is evident from monetary models of nominal exchange rates where the long-run neutrality of money holds. Nominal exchange rates and prices move together in an one-to-one proportional manner as a response to monetary shocks in the long-run even in sticky price type monetary models, such as the "Dornbusch overshooting model" (see Dornbusch, 1976).

\footnotetext{
${ }^{1}$ The definition of convergence, in this literature, hinges on the time series concept of stationarity. In this literature, stationarity is assumed to imply convergence irrespective of whether the underlying specification used in testing contains an intercept or a linear trend. This issue has attracted attention in the context of absolute or conditional convergence in the growth literature where the issue of convergence has been extensively analyzed, see Dufrénot, Mignon and Naccache (2009) and Stengos and Yazgan (2011) for a discussion of the different definitions of convergence.
} 
However, in the presence of real shocks, it may not be possible to predict the proportionality between prices and nominal exchange rates, even in the long-run, as suggested by $\mathrm{PPP}^{2}$. Rogoff (1996) emphasized the same issue referring to observed excess short-term volatility of real exchange rates. He pointed out that most explanations of short-term exchange rate volatility are based on financial factors such as portfolio preferences, short-term asset price bubbles, and monetary shocks. Furthermore, consensus estimates for the rate at which PPP exchange rates converge to their equilibrium levels suggest a half-life of three to five years, a period which is too long to rationalize on the basis of monetary factors (see Choi et al. (2006) and Murray and Papell (2005)). It is not difficult to rationalize the reasons behind the slow rate of long run PPP convergence on the basis of real shocks that stem from preferences and technology. However, existing models based on real shocks seem to be unable to explain short term exchange rate volatility. This issue is referred as "the purchasing parity power puzzle" by Rogoff (1996).

Some researchers have taken an alternative route by considering price-level convergence across regions that share a common currency. This approach provides a more controlled environment, as problems due to fluctuations in exchange rates or factor market rigidities are eliminated. By using disaggregated U.S. consumer prices, Parsley and Wei (1996) were able to show that half-life estimates range from 4 to 15 quarters, which is significantly faster than the typical estimates of the speed of convergence to PPP across countries. By using an updated version of the same data set Yazgan and Yilmazkuday (2011) provided evidence on, even, quicker convergence rates. However, as a sharp contrast to this result, Cecchetti et al (2002), estimated much larger half-life figures (amounting to 9 years!) by using consumer price indices of U.S. cities. In a recent study, Crucini and Shintani (2008) utilized a large disaggregated retail price data set covering several cities and countries around the world and provided half-life estimates around 18 months across US cities.

In these studies of real exchange rate convergence across countries/regions, the existence of a unit root in relative prices is tested by conducting panel unit root tests, and half lives are calculated based on the estimates of panel unit root regressions. The main problem here is the use of an arbitrary benchmark to construct relative prices. The usual practise is to use either an arbitrarily chosen country/region or an aggregate measure (i.e. the average of all countries/regions) as the benchmark. Crucini and Shintani (2008) is an exception; their analysis is based on panel regressions where the cross section units consist of all possible city pairs, hence their

\footnotetext{
${ }^{2}$ This can be explained by the following example (see De Grauwe 1996, p. 97). Let us suppose an improvement in the terms of trade of the home country following a shift in world preferences in favor of the products of that country. As a result, the country will experience an improvement in its current account position causing a need for real appreciation to re-equilibrate the current account. In this case, the nominal exchange rates and domestic prices may even move in opposite directions, whereas in a PPP framework they move in the same proportion.
} 
analysis is free of the arbitrary benchmark problem. However, their panel regressions assume homogeneous slopes across city pairs and cross sectional independence. Clearly, both of these assumptions are unlikely to hold in practice (see Pesaran et al 2009, p.500 for a critique of panel unit root tests). Pesaran et al (2009), by using the pairwise approach of Pesaran (2007), address these problems and find striking evidence on convergence ${ }^{3}$.

However, including Pesaran et al (2009), most of the empirical work, so far assumes that the empirical analysis of PPP can be carried out within a $I(0) / I(1)$ framework, yet it may be that a long memory framework is more appropriate for such an analysis ${ }^{4}$. If the real exchange rate actually follows a fractionally integrated process then empirical findings based on a simple $I(1) / I(0)$ classification will result in spurious inferences about convergence. Moreover in the standard $I(1) / I(0)$ analysis, when structural breaks are present standard tests of convergence may lack power to reject the null of nonstationarity. The same will be true for an ARFIMA process where the presence of structural breaks may contaminate the dynamics and the classification between different convergence cases depending on the estimates of the long memory parameter $d$.

More recently, Dufrénot, Mignon and Naccache (2009), henceforth DMN, also use fractional integration analysis to test GDP per capita convergence for a group of developing countries. They introduce an ARFIMA model and they allow for the long-memory parameter $d$ to be greater than 0.5 . In other words, they do not simply restrict $d$ to be in the interval $(-0.5,0.5)$ but they allow it to be also between 0.5 and 1 as well as greater than 1 . This gives rise to a rich classification of convergence cases and DMN are careful to examine the different cases that arise. Stengos and Yazgan (2011) extend the analysis carried out by DMN in two directions. First, that they do not rely as DMN on using a benchmark to construct measure output gaps and the second is that they allow for the presence of structural breaks something that was also not considered by DMN. The presence of structural breaks is important, since they will affect the time series properties of the series under consideration (see Perron (1989). In the standard $I(1) / I(0)$ analysis, when structural breaks are present standard tests of convergence may lack power to reject the null of nonstationarity. The same will be true for an ARFIMA process where the presence of structural breaks may contaminate the dynamics and the classification between different convergence cases depending on the estimates of the long memory parameter $d$. The issue of relying on a benchmark, also renders the analysis problematic as perceived leaders used as benchmark economies may not retain the leader title over the whole period of analysis. In that respect, Pesaran's (2007) pairwise analysis becomes relevant and useful to in this context. The rich classification of convergence cases based on long memory analysis and estimates of $d$ allows us

\footnotetext{
${ }^{3}$ Yazgan and Yilmazkuday (2011) use also the pairwise approach of Pesaran (2007).

${ }^{4}$ Cheung and Lai (1993) constitutes an exception.
} 
to also consider the different possible factors that affect the speed of convergence and obtain an economic interpretation of our findings. In explaining the speed of convergence of real exchange rates we find impediments to trade such as distance between neighbouring countries and sticky prices to be mainly responsible for the slow adjustment of real exchange rates of most country pairs to PPP rather than nominal rates. This gives us a direct way of assessing the significance of the main economic factors that affect convergence to equilibrium.

In this paper we use a long memory framework to examine the validity of PPP using both monthly and quarterly data for CPI weighted (real) exchange rates for a panel of countries over a fifty year period (1957 to 2009) ${ }^{5}$. We consider both types of data to check the robustness and sensitivity of our findings to the frequency used in the analysis and compare our findings with the results obtained in the literature using only one type. The analysis focusses on the long memory parameter $d$ that allows us to obtain different convergence classifications depending on its value. We conduct the analysis following Stengos and Yazgan (2011) in that we will allow for the presence of smooth structural breaks and as in Pesaran (2007) we do not rely on a benchmark. Our findings show evidence for convergence of the long memory mean reverting variety irrespective of the frequency used in the analysis. The paper is organized as follows. In section 2 we will present our analytical framework. Then, in section 3, we will proceed with the empirical results using both monthly and quarterly data. In section 4 we will try to explain the estimates of the long memory parameter $d$ by a number of long run characteristics that refer to macroeconomic policy variables that could affect differences in exchange rates. Finally, in section 5 , we will conclude.

\section{Testing framework with long memory.}

First we proceed as in Pesaran et al (2009), for countries $i=0,1,2, \ldots N$, with the U.S. as country zero, the logarithm of the real exchange rate between country $i$ and $j$ at time $t$ is given by

$$
q_{i j, t}=e_{i j, t}+p_{j, t}-p_{i, t}=\ln \left(E_{i j, t} P_{j, t} / P_{i, t}\right)
$$

where $E_{i j, t}$ is the nominal exchange rate (units of currency $i$ per unit of currency $j$ ) and $P_{j, t}$ and $P_{i, t}$ are price indices. The real rate against U.S. dollar is given by

$$
q_{i, t}=q_{i 0, t}=e_{i 0, t}+p_{0, t}-p_{i, t}
$$

\footnotetext{
${ }^{5}$ The source and the description of the data used and the countries covered in the study are given in Appendix B.
} 
Since $E_{i j, t}=E_{i, t} / E_{j, t}$ the real exchange rate between any other pair countries $i, j \neq 0$ can be calculated as

$$
q_{i j, t}=q_{i, t}-q_{j, t}
$$

PPP implies that $q_{i j, t}$ follows a mean reverting process. We will use the pairwise approach developed by Pesaran (2007) to test PPP as in Pesaran et al (2009). However we will not confine ourselves in $I(0) / I(1)$ framework by assuming

$$
q_{i, t}-q_{j, t}=\beta(t)+z_{t} \quad z_{t} \sim I(d), i=1, \ldots, N, i \neq j, t=1, \ldots, T
$$

The process $z_{t}$ is described as $(1-L)^{d} z_{t}=\varepsilon_{t}$, where, $L$ is the lag operator and $\varepsilon_{t}$ is an i.i.d. disturbance term. The fractional integration parameter is given by $d$ under the assumption that the process is invertible $(d>-0.5)$. The $\beta(t)$ function is a deterministic function of the time trend $t$. For example, in the $I(0)$ case, Pesaran et al (2009) assumed that this function is linear $\beta(t)=\beta_{0}+\beta_{1} t$ with and without $\beta_{1}=0$. When $\beta_{1} \neq 0$ the presence of this linear trend can be justified by making reference to Harrod-Samuelson-Balassa effects or measurement error in prices, particularly in the treatment of quality. Since our data covers a longperiod from 1957M1-2009M12, the presence of some (unknown) structural breaks is very likely. Therefore allowing the possibility of structural breaks by using an appropriate specification seems to be a worthwhile exercise. Hence, in our case, following Becker, Enders and Hurn (2004) and Becker, Enders and Lee (2006) and Ludlow and Enders (2000) we let the $\beta(t)$ function be defined in a way that it admits structural breaks.

$$
\beta(t)=\beta_{0}+\beta_{1} \sin \left(\frac{2 \pi k t}{T}\right)+\beta_{2} \cos \left(\frac{2 \pi k t}{T}\right)
$$

This functional form allows for the presence of (smooth) structural breaks. Note here that different values of $k$ will have different implications for the permanent or transitory nature of the breaks. If $k$ is an integer then this will result in temporary breaks, whereas fractional frequencies would imply permanent breaks as the function would not complete a full oscillation. One advantage of adopting this specification for structural breaks is that it does not require any prior knowledge on the dates those breaks occur. On the contrary, it assumes that breaks happen smoothly instead of abruptly, something that would make their detection more difficult.

DMN and Stengos and Yazgan (2011) distinguish between different convergence types depending on the different values of $d, \beta_{0}, \beta_{1}$ and $\beta_{2}$. In this paper we will analyse "detrended" data, since we first estimate the $\beta(t)$ function and then subtract it from the $q_{i j, t}$ series defined above. In that context we will operate within a conditional convergence framework, see DMN and Stengos and Yazgan (2011). However, in the presentation of the results we will only concentrate on the parameter $d$ as the main parameter of interest as it defines the time series properties of the process under investigation. For different values of $d$ : 
Case 1: $-0.5<d \leq 0$. This is the case of a "short memory process, where there is "fast convergence" or "short memory convergence".

Case 2: $0<d<0.5$. This is the case of a long memory process, but still stationary process, where there is a slow or smooth decay in the convergence process. Here, real exchange rate differences (both measured against US dollars) in the remote past will linger on in the current real exchange rate difference, although with a smaller influence.

Case 3: $0.5<d<1$. This is the case of a long memory process, which is non-stationary but still mean reverting. In that case the process is characterized by high persistence, whereby any real exchange rate differences in the distant past will still have a long-lasting influence in the present.

Case 4: $d \geq 1$. This is the case of an explosive process. This is the situation where there is a strong magnification effect and any initial difference is not expected to be reversed in the future. This is the case of "stochastic divergence".

The above definitions of the different convergence cases allow for a much richer classification of convergence types, whereby one can distinguish between stationary convergence and mean reverting non-stationary convergence. An additional feature of this classification scheme is that it allows for initial differences either to linger on and have a long lasting influence in the present or decay rapidly and play no role or be somewhere in-between these two cases. This is something that can not be captured by the simple $I(0) / I(1)$ classification where there are only two extreme cases, that is perfect persistence or no persistence at all. In our case we will concentrate on the four cases that depend on the values of $d$.

\subsection{Testing for convergence.}

We proceed as in Stengos and Yazgan (2011) to estimate the long memory parameter $d$ by a variety of different estimators. Let $I_{z}\left(\omega_{j}\right)$ denote the periodogram of a series $z_{t}$ based on a discrete Fourier transform $W_{z}\left(\omega_{j}\right)$ at frequency $\omega_{j}=\frac{2 \pi j}{T}$ for $j=0, \ldots T-1$, such that $I_{z}\left(\omega_{j}\right)=W_{Z}\left(\omega_{j}\right) W_{z}^{*}\left(\omega_{j}\right)$ with $W_{z}^{*}\left(\omega_{j}\right)$ being the complex conjugate of $W_{z}\left(\omega_{j}\right)$ defined as

$$
W_{z}\left(\omega_{j}\right)=\frac{1}{\sqrt{2 \pi T}}\left|\sum_{t=1}^{T} z_{t} e^{i t \omega_{j}}\right|^{2}
$$

The discrete Fourier transform $W_{z}\left(\omega_{j}\right)$ can be used to define a Whittle estimator of $d$ obtained by minimizing the objective function below with respect to $d$ :

$$
W H(G, d)=\frac{1}{v} \sum_{j=1}^{v}\left(\ln \left(G \omega_{j}^{-2 d}\right)+\frac{I_{z}\left(\omega_{j}\right) \omega_{j}^{2 d}}{G}\right), G \in(0, \infty)
$$


where $v$ is the number of frequencies used in the estimation. The most well known Whittle estimator that is valid under nonstationarity is Exact Local Whittle (ELW) estimator of Shimotsu and Phillips (2005,2006). This estimator is consistent and has the same $N\left(0, \frac{1}{4}\right)$ limit values for all values of $d$. The word "exact" is used to distinguish this estimator, which relies on exact algebraic manipulation, from the conventional Local Whittle of Kuensch (1987) and Robinson (1995) (LW), which is based on an approximation of Whittle likelihood function and is not a good generalpurpose estimator when the value of $d$ may take on values in the non-stationary zone beyond $\frac{3}{4} \cdot 6$

However, the ELW estimator has also been shown to have some undesirable properties. As shown by Shimotsu (2008), if an unknown mean (initial value) is replaced by its sample average, simulations suggest that the ELW estimator is inconsistent for $d>1$. Furthermore, if an unknown mean is replaced by the first observation, the consistency and normality of ELW estimator for $d \in\left(0, \frac{1}{2}\right)$ requires a strong assumption on the number of ordinates used in estimation, and simulations suggest that the estimator is inconsistent for $d \leq 0$. Hence, an unknown mean needs to be estimated carefully in the ELW estimation. Shimotsu (2008) modifies the ELW objective function to estimate the mean by combining two estimators: the sample average and the first observation and denotes the resulting estimator as 2 Stage Feasible Exact Local Whittle (2FELW). The 2FELW estimator, which uses the tapered estimator of Velasco (1999) in the first stage, has the same $N\left(0, \frac{1}{4}\right)$ limit distribution for $d \in\left(-\frac{1}{2}, 2\right)$ and is consistent when $d>\frac{1}{2}$. Moreover, the finite sample performance of the 2FELW estimator inherits the desirable properties of the ELW estimator. This estimator can be also computed with prior detrending (2FELWd) of the data, see Shimotsu (2008). Finally we also apply the fully extended local Whittle estimator (FELW) of Abadir et al. (2007), which uses a fully extended discrete Fourier transform. The FELW estimator is shown to be consistent and has a $N\left(0, \frac{1}{4}\right)$ distribution for $d \in\left(-\frac{3}{2}, \infty\right)$. As in the case of 2FELWd, the FELW estimator is also computed with prior detrending (FELWd). The 2FELW and FELW estimators can be regarded as being complementary to each other for a variety of reasons. The FELW estimator has the advantage over the 2FELW estimator in that it covers a wider range of $d$, and it does not require estimating the mean. However, the FELW estimator excludes the values of $d=\frac{1}{2}, \frac{3}{2}, \ldots$, which results in "holes" in the confidence intervals at these points, whereas the two-step approach does not (see Shimotsu, 2008, for a comprehensive comparison and discussion of the two estimators). ${ }^{7}$

\footnotetext{
${ }^{6}$ Although these estimators are consistent for $d \in\left(\frac{1}{2}, 1\right)$ asymptotically normally distributed for $d \in\left(\frac{1}{2}, \frac{3}{4}\right)$, they are also known to exhibit nonstandard behavior when $d>\frac{3}{4}$. For instance, they have a non-normal limit distribution for $d \in\left(\frac{3}{4}, 1\right)$, and they converge to unity in probability and are inconsistent for $d>1$ (see Shimotsu and Phillips 2005,2006)

${ }^{7}$ Hence, FEWL estimators cannot be used under the null hypothesis of test 3 below. Never-
} 
All LW, ELW FELW, FELWd, 2FELW, 2FELWd estimators are used to estimate $d$ and $v$ is chosen as $v=T^{0.6}$ as suggested by Shimotsu (2008). ${ }^{8}$ Then, following DMN, we perform the following tests:

Test 1: $H_{0}^{0}: d=0$ against $H_{1}^{0}: d>0$ (short memory against long memory)

Test 2a: $H_{0}^{1 / 2 a}: d=0.5$ against $H_{1}^{1 / 2 a}: d<0.5$ ("limit" stationary long memory against stationary convergence)

Test 2b: $H_{0}^{1 / 2 b}: d=0.5$ against $H_{1}^{1 / 2 b}: d>0.5$ ("limit" stationary long memory against non-stationary convergence or mean reverting process)

Test 3: $H_{0}^{1}: d=1$ against $H_{1}^{1}: d<1$ (unit root against a mean reverting process)

Test 4: $H_{0}^{1}: d=1$ against $H_{1}^{1 \exp l}: d>1$ (unit root against stochastic divergence)

\subsection{Monte Carlo based critical values.}

We conduct Monte Carlo simulations to compute the critical values of the statistic corresponding to each of the above tests under the null hypothesis under consideration. The test statistic is computed as

$$
\frac{\sqrt{v}\left(\widehat{d}-d_{0}\right)}{\sigma(\widehat{d})}
$$

where, $d_{0}$ is the value of $d$ under the null hypotheses outlined above, $\widehat{d}$ is the estimate of $d$ and $\sigma(\widehat{d})$ its asymptotic standard error. For the simulations of the critical values, we consider 50000 iterations. For each iteration we generate a series from $z_{t} \sim I(d)$ for different values of $d$ corresponding to the different null hypotheses listed above. Note that in this case we do not rely on a specific $\beta(t)$-function with particular parametric values of the $\beta$-parameters to obtain the critical values of the various test statistics. The latter will be obtained on the assumption that we are looking at "de-trended" data.

Under asymptotic theory provided in Shimotsu (2008) among others, all the Whittle estimators considered here, except LW, which exhibits nonstandard behavior when $d>3 / 4$, are distributed as $N\left(0, \frac{1}{4}\right)$ under all of the null hypotheses defined above. Hence the above test statistic is expected to be distributed as standard normal under each null. Therefore the purpose of the present Monte Carlo analysis is to control for small sample deviations from the asymptotic distribution. In Table

theless we still used them for this case also for completeness as they yielded similar results to the others.

${ }^{8}$ The results remain qualitatively same across different choices of $v$ such as $v=T^{0.50,0.55,0.65,0.7}$ 
A1 of the Appendix A we provide critical values at 5 and 10 percent significance levels for $T=100,200,500^{9}$. These critical values are then used in the empirical analysis that follows.

\section{Empirical Findings.}

The data consists of monthly real exchange rate data for the period 1957M12009M12 and for 47 countries $(T=636 ; N+1=47)$ indexed as $i=0,1,2, \ldots, N$ with US being country 0 . However, $T=636$ should be treated as a maximum in our data set since data are not available for all countries for the whole period. The detailed description of the data is given in the Appendix B. The four tests outlined above are applied to all possible pairs of $q_{i j, t}, i=0,1,2, \ldots, N-1$, and $j=0,1,2, \ldots, N$. We first investigate persistence in real exchange rates data for the whole period and then separately as belonging to 2 different periods: 1957M1-1973M12 $(T=204 ; N=39)$, under the Bretton Woods system where many countries maintained fixed exchange rates against the U.S Dollar and 1974M1-2009M12 $(T=432 ; N=47)$, when floating rates became more common. Due to missing data, some countries are excluded from the data set in the analysis of $1957 \mathrm{M} 1-1973 \mathrm{M} 12^{10}$. We also look, as in Pesaran et al (2009), at the case of quarterly data in order to be able to more accurately compare our results with theirs.

We will analyze the nature of convergence depending on the classification presented Table 1 below. As in Pesaran et al (2009), we analyze real exchange convergence across 47 countries by considering all $(N+1) N / 2=1081$ real exchange rate pairs. Under the null hypothesis of each test, we would expect the fraction of real exchange rate pairs for which the null hypothesis is rejected to be close to the size of the test applied to the individual output gap pairs. Hence, in the tables rejection frequencies that greatly exceed a nominal size of say 0.05 or 0.10 would be taken as evidence against the null. Conversely, rejection frequencies that are less than the nominal size value will be taken as evidence in favor of the null ${ }^{11}$.

\footnotetext{
${ }^{9}$ It becomes clear from the table that the quantiles of the reported distributions converge to those of the standard normal as $T$ increases, but slowly and show significant differences across estimators. The graphics and some summary statistics of these distributions are available upon request.

${ }^{10}$ These countries are: Brazil, China, Hong Kong, Costa Rica, Hungary, Iran, Ireland, Saudia Arabia.

${ }^{11}$ Although, the underlying individual tests are not cross-sectionally independent, under the null, the fraction of rejections is expected to converge to $\alpha$, as $N$ and $T \rightarrow \infty$, where $\alpha$ is the size of the underlying test.
} 


\subsection{Detrending for structural breaks}

To control for structural breaks we detrend the data by estimating the $\beta_{0}, \beta_{1}, \beta_{2} s$ in (3) for 30 different values of $k=0.1,0.2,0.3, \ldots ., 2.9,3.0$ and by subtracting the estimated $\beta(t)$ function from the data series $q_{i j, t}$ before estimating the $d^{\prime} s$ and performing the different tests. Detrending for structural breaks after estimating the $\beta(t)$-function avoids the problem of having to rely on specific values of the $\beta$-parameters to obtain critical values in the simulations. Hence the test results will avoid possible misspecification due to the reliance on "incorrect" $\beta$ parameter values.

\subsection{Pair-Wise Results for Real Exchange Rates.}

Table 1 below summarizes the results of the tests above applied to all 1081 real exchange rate gap pairs over the periods 1957M1-2009M12 $(T=636 ; N=47)$, 1974M1-2009M12 $(T=432 ; N=47)$ and 1957M1-1973M12 $(T=204 ; N=39)$ at the 5 percent significance level ${ }^{12}$. The table shows the minimum (Min), median (Med) and maximum (Max) of rejection frequencies of the different tests using the critical values from Table A1.

\section{Table 1}

As can be seen from Table 1 all the maximum, median and even minimum of rejection frequencies of test 1 are well above the significance level (0.05) for the whole (1957-2009) and 1957-1973 period, for all four estimators of the $d$ parameter $^{13}$. The results suggest that for the different exchange rate regimes the persistence properties of the real series are quite similar. That suggests that in the presence of fixed exchange rates the adjustment was mainly done by prices whereas in the flexible exchange rates regime it is done by nominal exchange rates. The results for test 2 a suggest that we cannot reject the null hypothesis of $d=0.5$ against the hypothesis that $d<0.5$ for any period. Hence, there is evidence strongly in favor of "limit" stationary long memory as all the rejection frequencies are well below the significance level for all periods. However, the results for test $2 \mathrm{~b}$ reject that $d$ equals 0.5 and points towards $d>0.5$. The results from test 3 reject the

\footnotetext{
${ }^{12}$ To conserve space we only report the results of the FELW, FELWd, 2FELW and the 2FELWd estimators as the other two estimators give very similar results. We also do not report the results for the 10 percent significance level for the same reason. These results are available upon request.

As mentioned above FELWd and 2FELWd apply (linear) prior detrending the data. Therefore we also control for linear trends that may be present in the data via these estimators.

We accept $v=T^{0.6}$ as suggested by Shimotsu (2008).

${ }^{13}$ We use $T=500$ critical values.
} 
unit root hypothesis, especially for the 1957-1974 period and test 4 does not find evidence in favour of an explosive alternative, even though the rejection of the unit root hypothesis is not very decisive with the minimum rejection frequencies being higher than 0.05 but very close to 0.10 . Overall the evidence strongly points to the presence of a long memory process, where $0.5 \leq d<1$. The implication of our results is that we find long memory mean reverting convergence, something that is also consistent with Pesaran et al (2009).

\subsection{Evidence from Quarterly Data}

The evidence found for the monthly data suggests the presence of convergence, but of the long memory mean reverting variety. To directly compare our findings with those of Pesaran et al (2009) we also repeat the analysis with the quarterly data for 42 countries over the same time period. The results are presented in Table 2 and are qualitatively quite similar to those of the monthly series. They confirm the pattern found in the monthly data, that is the presence of a long memory process with $0.5 \leq d<1$. That establishes the presence of long memory mean reverting convergence in the data.

Table 2

\subsection{Pesaran's Measures of Pair-Wise Convergence.}

For the above monthly and quarterly data we also look at the Pesaran's (2007) measures of pair-wise convergence, which were also used by Stengos and Yazgan (2011)

$$
D_{t}^{2}=\frac{2}{N(N-1)} \sum_{i=1}^{N-1} \sum_{j=i+1}^{N}\left(q_{i, t}-q_{j, t}\right)^{2}
$$

and

$$
M D_{t}=\frac{2}{N(N-1)} \sum_{i=1}^{N-1} \sum_{j=i+1}^{N}\left|q_{i, t}-q_{j, t}\right|
$$

The first measure captures the notion of $\sigma$-convergence and the second one is related to the Gini coefficient. Both of these measures use all pairs of real exchange rates and plotting them allows for a quick view of the presence of convergence patterns consistent with $\sigma$-convergence. Figures 1 and 2 present the graphs of $D^{2}$ 
and $M D$ respectively for the monthly and quarterly series. The evidence for the monthly series shows evidence of nonstationary behavior and upward drifting in the averaged squared differences and it is not possible to observe mean reversion. However, this is not the case for the quarterly data, where there is strong evidence of a stable second moment over the period, even though there is no clear evidence of $\sigma-$ convergence. It is clear from the figures that the graphs display evidence of nonstationarity but that mean reversion would be easier to detect in the quarterly series, where the the averaged squared differences, capturing the second moment, appear stable. These findings are consistent with the results of a long memory mean reverting process that we found earlier.

Figure 1 and 2

\section{Determinants of persistence.}

The above analysis strongly points to the presence of high persistence in real exchange rates. In this section we analyze the determinants of this persistence by running the following regression

$\hat{d}_{i j}=\gamma_{0}+\gamma_{1} D I S_{i j}+\gamma_{2} L A N_{i j}+\gamma_{3} B O R_{i j}+\gamma_{4} T R A D E_{i j}+\gamma_{5} I N F_{i j}+\gamma_{6} E X_{i j}+u_{i j}, i=1, \ldots, N, i \neq j$

The $\hat{d}_{i j}^{\prime} s$ refer to the estimated $d$ for the $i j$ pairs obtained in the previous analysis and $u_{i j}$ represents the error term that could be cross sectionally correlated and possibly heteroskedastic. As regressors we consider the effect of transportation costs proxied by the logarithm of geographical distance between capital cities $(D I S)$, the common language $(L A N)$ and the shared border $(B O R)$ dummies which have a value equal to one when both countries speak the same official language and when the trading partners share a border. A higher value of $d$, represents a less convergent (and possibly divergent) real exchange rate. Hence, we expect that estimated $\hat{d}$ is positively related with $D I S$ but negatively related with the others $\left(\gamma_{1}>0 ; \gamma_{2}, \gamma_{3}<0\right)$. TRADE shows the time average of the sum of trade flows for the $i j$ country pair relative to their GDPs. INF and $E X$ represent volatilities measured by the standard deviation (over time) of the sum of inflation and growth rates of nominal exchange rates for the partner countries $i j$. We expect that the larger the value of these variables for the $i j$ country pair, the smaller the value of the $\hat{d}_{i j}$ for that pair, since more variability (or volatility) in prices and nominal exchanges rates would certainly be helpful for restoring PPP with high rates of 
convergence. Similarly, it is possible to argue that higher trade among country pairs would act in favor of higher rates of convergence. As such we expect the signs of $\gamma_{4}, \gamma_{5}$ and $\gamma_{6}$ to be negative. We run the above regression using $\hat{d}^{\prime}$ 's obtained from monthly data over 780 country pairs, for the period of 1974-2009. ${ }^{14}$. Figure 3 reports the map of all pairs that are governed by slow and rapid convergence according to the estimated $d$ values and Table 3 that reports the same results for these pairs for the period under examination. Even though it is difficult to draw clear cut conclusions from these results, it is evident for example that China has been slow to converge as it pursues a policy of undervaluing its currency, something that does not follow from its trade balances with the rest of the world that have been becoming stronger over time. Similarly, most European countries experience fast convergence in their real exchange rates when dealing with the rest of the world and among themselves as there have been policies in place for European integration.

Figure 3 and Table 3

The OLS estimation yields the following estimated coefficients with their associated $H A C$ t-values reported in Table 4 below.

\section{Table 4}

The first panel of the table reports the estimates obtained from the all country pairs. As can be seen above only $D I S$ and $E X$ are statistically significant with the anticipated signs. TRADE is insignificant at 10 percent significance level with an "incorrect" $\operatorname{sign}^{15}$. It is worth noting that $D I S$ could be taken as a proxy for trade balances between neighbouring countries, where a large distance acts as an impediment to trade. The fact that $E X$, but not $I N F$, is found significant can be interpreted as sticky prices being mainly responsible for slow adjustment of real exchange rates to PPP rather than nominal rates. In the following panels the same regression is also estimated for different regions. It becomes apparent that the pattern of results from all regions except Asia are similar to the overall one, with $E X$ being the most important factor behind the adjustment to equilibrium. For Asia though it seems that prices are more important than nominal exchange rates as well as $T R A D E$, something that is consistent with China's actions over the period ever since it has become a dominant force in world trade

\footnotetext{
${ }^{14}$ The reported results were obtained by using 2FELW estimator of $d$. However we obtained qualitatively similar results with other 3 estimators (FELW,FELWd, 2FELWd) of $d$. The 780 pairs is obtained from 40 countries by excluding Colombia, Costa Rica, Egypt, Pakistan, Sri Lanka, Trinidad, and Uruguay from 47 countries which can be found in Appendix B.

${ }^{15}$ This result may due to the problems in constructing the trade data as explained in Appendix B.
} 


\section{Conclusions.}

In this paper we use a long memory framework to examine the validity of PPP using both monthly and quarterly data for a panel of countries over a fifty year period (1957 to 2009). The analysis focusses on the long memory parameter $d$ that allows us to obtain different convergence classifications depending on its value. We conduct the analysis following Stengos and Yazgan (2011) in that we will allow for the presence of smooth structural breaks and as in Pesaran (2007) we do not rely on a benchmark. Our findings show evidence for convergence of the long memory mean reverting variety, something that is in broad agreement with Pesaran et al (2009) who also found evidence of convergence within a $I(0) / I(1)$ framework. In explaining the speed of convergence as captured by the estimated long memory parameter $d$ we find impediments to trade such as distance between neighboring countries and sticky prices to be mainly responsible for the slow adjustment of real exchange rates to PPP rather than nominal rates for all country groups but Asia, where the opposite is true. 


\section{References}

[1] Abadir K.,Talmain G., 2002. Aggregation, Persistence and Volatility in a Macro Model. Review of Economic Studies. 69, 749-779.

[2] Abadir K., Distaso W., Giraitis L., 2007. Nonstationarity-extended local Whittle estimation. Journal of Econometrics. 141, 1353-1384.

[3] Becker R., Enders W., Hurn S., 2004. A General Test for Time Dependence in Parameters. Journal of Applied Econometrics. 19, 899-906.

[4] Becker R., Enders W., Hurn S., 2006. A stationary Test in the Presence of an Unknown Number of Smooth Breaks. Journal of Time Series Analysis. 27, 381-409.

[5] Cecchetti S.G., Nelson C.M., Robert J.S., 2002. Price Index Convergence among United States Cities. International Economic Review. 43, 1081-99.

[6] Choi C.Y., Mark N.C., Sul D., 2006. Unbiased estimation of the half-life to PPP convergence in panel data. Journal of Money, Credit and Banking. 38, 921-938.

[7] Crucini M.J., Shintani M., 2009. Persistence in law of one price deviations: Evidence from micro-data. Journal of Monetary Economics. 55, 629-644.

[8] Dees S.D., DiMauro F., Pesaran M.H., Smith V., 2007. Exploring the International Linkages of the Euro Area: a Global VAR Analysis. Journal of Applied Econometrics. 22, 1-38

[9] Dornbusch R.,1976, Expectations and Exchange Rate Dynamics. Journal of Political Economy 84 (6): 1161-1176

[10] Dufrénot G., Mignon V., Naccache T., 2009. The slow convergence of per capita income between the developing countries: "growth resistance" and sometimes "growth tragedy". Working Paper 09/03, Centre for Research in Economic Development and International Trade,University of Nottingham

[11] Durlauf S.N., Johnson P.A., Temple J.R.W., 2006. Growth econometrics. In Handbook of Economic Growth, Aghion P, Durlauf SN. (eds). North Holland, Amsterdam.

[12] Geweke J., Porter-Hudak S., 1983. The Estimation and Application of Long Memory Time Series Models. Journal of Time Series Analysis, 4, 221-238. 
[13] Frankel J.A., Rose A.K., 1996. A panel project on purchasing power parity: mean reversion within and between countries. Journal of International Economics. 40, 209-224.

[14] Levin, A., Lin, C.F. and C.-S. Lu, (2002), "Unit root tests in panel data: asymptotic and finite-sample properties", Journal of Econometrics, 108, 1-24

[15] Ludlow J., Enders W., 2000. Estimating Non-Linear ARMA models using Fourier Coefficients. International Journal of Forecasting. 16, 333-347.

[16] Kuensch H., 1987. Statistical aspects of self-similar processes. In Proceedings of the First World Congress of the Bernoulli Society, Prokhorov Y, Sazanov VV. (eds). VNU Science Press, Utrecht.

[17] Murray C.J., Papell D.H., 2005. Do panels help solve the purchasing power parity puzzle? Journal of Business and Economic Statistics. 23, 410-415.

[18] Perron, P. (1989), "The great crash, the oil price shock, and the unit root hypothesis" Econometrica, 57,.1361-1401

[19] Pesaran M.H., 2007. A pair-wise approach for testing output and growth convergence. Journal of Econometrics. 138, 312-355.

[20] Pesaran M.H., Smith R.P., Yamagata T., Hvozdyk L., 2009. Pairwise Tests of Purchasing Power Parity. Econometric Reviews. 28, 495-521

[21] Robinson P.M.,1995. Gaussian semiparametric estimation of long range dependence. Annals of Statistics. 23, 1630-1661.

[22] Rogoff K., 1996. The Purchasing Power Parity Puzzle. Journal of Economic Literature. 34, 647-668.

[23] Shimotsu K., Phillips P.C.B., 2005. Exact local Whittle estimation of fractional integration. Annals of Statistics. 33, 1890-1933.

[24] Shimotsu K., Phillips P.C.B., 2006. Local Whittle estimation of fractional integration and some of its variants. Journal of Econometrics. 130, 209-233.

[25] Shimotsu K., 2008. Exact Local Whittle Estimation of Fractional Integration with Unknown Mean and Time Trend. Econometric Theory, forthcoming.

[26] Smith A., 2005. Level Shifts and the Illusion of Long Memory in Economic Time Series. Journal of Business $8 \mathcal{F}$ Economic Statistics. 23, 321-333.

[27] Stengos T., Yazgan M.E., 2011. Persistence in Convergence. Working Paper 1105, University of Guelph, Department of Economics 
[28] Taylor A.M., Taylor M.P., 2004. The Purchasing Power Parity Debate. Journal of Economic Perspectives. 18, 135-158.

[29] Velasco C., 1999. Gaussian semiparametric estimation of non-stationary time series. Journal of Time Series Analysis. 20, 87-127.

[30] Yazgan M.E., Yilmazkuday H., 2011. Price Level Convergence: New Evidence from U.S. Cities. Economics Letters. 110, 76-78. 


\section{Tables and Figures}

Table 1: Rejection frequencies for convergence statistics (monthly data).

\begin{tabular}{|c|c|c|c|c|c|c|c|c|c|c|c|c|c|c|c|}
\hline \multicolumn{16}{|c|}{$1957-1974$} \\
\hline & \multicolumn{3}{|c|}{ Test1 } & \multicolumn{3}{|c|}{ Test2a } & \multicolumn{3}{|c|}{ Test2b } & \multicolumn{3}{|c|}{ Test3 } & \multicolumn{3}{|c|}{ Test4 } \\
\hline Esitmator & Min & Med & Max & Min & Med & Max & Min & Med & Max & Min & Med & Max & Min & Med & Max \\
\hline FELW & 0.983 & 0.986 & 0.992 & 0.013 & 0.020 & 0.026 & 0.774 & $\mid 0.799$ & 0.823 & 0.198 & 0.221 & 0.256 & 0.070 & 0.080 & 0.085 \\
\hline FELWd & 0.979 & 0.984 & 0.988 & 0.013 & 0.021 & 0.028 & $\mid 0.787$ & 0.805 & 0.816 & 0.212 & 0.224 & 0.249 & 0.070 & 0.080 & 0.085 \\
\hline 2 FELW & 0.982 & 0.985 & 0.991 & 0.014 & $\mid 0.021$ & 0.028 & 0.802 & 0.822 & 0.841 & 0.208 & 0.229 & 0.258 & 0.070 & 0.080 & 0.085 \\
\hline 2FELWd & 0.979 & 0.983 & 0.987 & 0.013 & 0.022 & 0.028 & 0.806 & 0.824 & 0.834 & 0.214 & 0.227 & 0.251 & 0.070 & 0.080 & 0.086 \\
\hline
\end{tabular}

\begin{tabular}{|l|c|c|c|c|c|c|c|c|c|c|c|c|c|c|c|}
\hline \multicolumn{10}{|c|}{$1974-2009$} \\
\hline & \multicolumn{3}{|c|}{ Test1 } & \multicolumn{4}{|c|}{ Test2a } & \multicolumn{3}{c|}{ Test2b } & \multicolumn{3}{c|}{ Test3 } & \multicolumn{3}{c|}{ Test4 } \\
\hline Esitmator & Min & Med & Max & Min & Med & Max & Min & Med & Max & Min & Med & Max & Min & Med & Max \\
\hline FELW & 1.000 & 1.000 & 1.000 & 0.000 & 0.000 & 0.000 & 0.963 & 0.970 & 0.977 & 0.095 & 0.105 & 0.117 & 0.077 & 0.083 & 0.088 \\
\hline FELWd & 1.000 & 1.000 & 1.000 & 0.000 & 0.000 & 0.000 & 0.967 & 0.974 & 0.980 & 0.088 & 0.099 & 0.109 & 0.077 & 0.084 & 0.089 \\
\hline 2FELW & 1.000 & 1.000 & 1.000 & 0.000 & 0.000 & 0.000 & 0.967 & 0.973 & 0.980 & 0.095 & 0.105 & 0.117 & 0.077 & 0.083 & 0.088 \\
\hline 2FELWd & 1.000 & 1.000 & 1.000 & 0.000 & 0.000 & 0.000 & 0.971 & 0.977 & 0.983 & 0.088 & 0.099 & 0.109 & 0.077 & 0.084 & 0.089 \\
\hline
\end{tabular}

\begin{tabular}{|c|c|c|c|c|c|c|c|c|c|c|c|c|c|c|c|}
\hline \multicolumn{16}{|c|}{ 1957-2009 } \\
\hline & \multicolumn{3}{|c|}{ Test1 } & \multicolumn{3}{|c|}{ Test2a } & \multicolumn{3}{|c|}{ Test2b } & \multicolumn{3}{|c|}{ Test3 } & \multicolumn{3}{|c|}{ Test4 } \\
\hline Esitmator & Min & Med & Max & Min & Med & Max & Min & Med & Max & Min & Med & Max & Min & Med & Max \\
\hline FELW & 1.000 & 1.000 & 1.000 & 0.000 & 0.000 & 0.000 & 0.981 & 0.984 & 0.987 & 0.130 & 0.138 & 0.144 & 0.109 & \begin{tabular}{|l|}
0.116 \\
\end{tabular} & \begin{tabular}{|l|}
0.121 \\
\end{tabular} \\
\hline$\overline{\text { FELWd }}$ & 1.000 & 1.000 & 1.000 & 0.000 & 0.000 & 0.000 & $\mid 0.982$ & 0.985 & 0.988 & 0.126 & 0.133 & 0.138 & 0.109 & $\mid 0.116$ & \begin{tabular}{|l|}
0.121 \\
\end{tabular} \\
\hline 2 FELW & 1.000 & 1.000 & 1.000 & 0.000 & 0.000 & 0.000 & 0.985 & 0.988 & 0.990 & 0.130 & 0.138 & 0.144 & 0.109 & 0.116 & 0.121 \\
\hline 2FELWd & 1.000 & 1.000 & 1.000 & 0.000 & 0.000 & 0.000 & 0.987 & 0.989 & .991 & .126 & 0.133 & 0.138 & 0.109 & 0.116 & 0.121 \\
\hline
\end{tabular}

Notes: FELW: Feasible Exact Local Whittle estimator, FELWd: Feasible Exact Local Whittle estimator with detrending, 2FELW: 2-Stage Feasible Exact Local Whittle estimator, 2FELWd: 2-Stage Feasible Exact Local Whittle estimator with detrending. Tests are conducted at 5 percent significance levels with $T=500$ critical values and simulations are carried out by assuming $v=T^{0.6}$. 
Table 2: Rejection frequencies for convergence statistics (quarterly data).

\begin{tabular}{|c|c|c|c|c|c|c|c|c|c|c|c|c|c|c|c|}
\hline \multicolumn{16}{|c|}{ 1957-1974 } \\
\hline & \multicolumn{3}{|c|}{ Test1 } & \multicolumn{3}{|c|}{ Test2a } & \multicolumn{3}{|c|}{ Test2b } & \multicolumn{3}{|c|}{ Test3 } & \multicolumn{3}{|c|}{ Test4 } \\
\hline Esitmator & Min & \begin{tabular}{|l|} 
Med \\
\end{tabular} & Max & Min & Med & Max & Min & Med & Max & Min & Med & Max & Min & Med & Max \\
\hline FELW & 0.942 & \begin{tabular}{|l|}
0.958 \\
\end{tabular} & 0.977 & 0.019 & 0.033 & 0.050 & 0.655 & \begin{tabular}{|l|}
0.722 \\
\end{tabular} & \begin{tabular}{|l|l|}
0.747 \\
\end{tabular} & $\mid 0.154$ & \begin{tabular}{|l|}
0.183 \\
\end{tabular} & 0.258 & \begin{tabular}{|l|}
0.098 \\
\end{tabular} & \begin{tabular}{|l|}
0.137 \\
\end{tabular} & $\mid 0.146$ \\
\hline FELWd & 0.940 & 0.950 & 0.959 & 0.028 & 0.033 & 0.043 & $\mid 0.679$ & $\mid 0.727$ & 0.744 & 0.200 & 0.213 & 0.253 & 0.098 & 0.135 & 0.145 \\
\hline 2 FELW & 0.900 & $\mid 0.923$ & 0.953 & 0.039 & 0.061 & 0.091 & 0.624 & 0.694 & 0.736 & 0.223 & 0.260 & 0.320 & 0.094 & 0.136 & 0.146 \\
\hline 2 FELWd & 0.899 & $\mid 0.910$ & 0.923 & 0.055 & 0.062 & 0.075 & 0.643 & $\mid 0.691$ & 0.713 & 0.260 & $\mid 0.279$ & 0.319 & 0.094 & 0.134 & 0.144 \\
\hline
\end{tabular}

\begin{tabular}{|c|c|c|c|c|c|c|c|c|c|c|c|c|c|c|c|}
\hline \multicolumn{16}{|c|}{ 1974-2008 } \\
\hline & \multicolumn{3}{|c|}{ Test1 } & \multicolumn{3}{|c|}{ Test2a } & \multicolumn{3}{|c|}{ Test2b } & \multicolumn{3}{|c|}{ Test3 } & \multicolumn{3}{|c|}{ Test4 } \\
\hline Esitmator & Min & Med & Max & Min & Med & Max & Min & Med & Max & Min & Med & Max & Min & Med & Max \\
\hline FELW & 0.997 & 0.998 & $\mid 0.998$ & 0.002 & 0.002 & 0.003 & 0.789 & \begin{tabular}{|l|}
0.796 \\
\end{tabular} & 0.816 & 0.216 & 0.249 & 0.257 & 0.026 & 0.030 & 0.032 \\
\hline FELWd & 0.997 & 0.998 & 0.998 & 0.002 & 0.002 & 0.003 & 0.800 & 0.810 & 0.832 & 0.208 & 0.236 & 0.243 & 0.026 & 0.030 & 0.032 \\
\hline 2FELW & 0.996 & 0.997 & 0.997 & 0.003 & 0.003 & 0.004 & 0.827 & 0.832 & 0.849 & 0.221 & 0.255 & 0.263 & 0.026 & 0.030 & 0.032 \\
\hline 2 FELWd & 0.997 & 0.997 & \begin{tabular}{|l|}
0.998 \\
\end{tabular} & 0.003 & $\mid 0.004$ & .004 & 0.837 & 0.843 & .861 & .213 & 0.241 & 0.248 & .026 & 0.030 & 0.032 \\
\hline
\end{tabular}

\begin{tabular}{|c|c|c|c|c|c|c|c|c|c|c|c|c|c|c|c|}
\hline \multicolumn{16}{|c|}{$1957-2008$} \\
\hline & \multicolumn{3}{|c|}{ Test1 } & \multicolumn{3}{|c|}{ Test2a } & \multicolumn{3}{|c|}{ Test2b } & \multicolumn{3}{|c|}{ Test3 } & \multicolumn{3}{|c|}{ Test4 } \\
\hline Esitmator & Min & Med & Max & Min & Med & Max & Min & Med & Max & Min & Med & Max & Min & Med & Max \\
\hline FELW & 0.998 & $\mid 0.999$ & $\mid 0.999$ & $\mid 0.001$ & 0.002 & $\mid 0.002$ & $|0.795|$ & 0.811 & $\mid 0.837$ & 0.268 & $\mid 0.287$ & 0.300 & 0.014 & 0.020 & 0.022 \\
\hline FELWd & 0.998 & $\mid 0.998$ & 0.999 & 0.001 & 0.002 & $\mid 0.002$ & 0.809 & 0.819 & 0.830 & 0.265 & 0.279 & 0.290 & 0.014 & 0.020 & 0.021 \\
\hline 2 FELW & \begin{tabular}{|l|}
0.997 \\
\end{tabular} & 0.998 & \begin{tabular}{|l|}
0.998 \\
\end{tabular} & \begin{tabular}{|l|}
0.002 \\
\end{tabular} & 0.003 & \begin{tabular}{|l|}
0.003 \\
\end{tabular} & \begin{tabular}{|l|}
0.852 \\
\end{tabular} & \begin{tabular}{|l|}
0.863 \\
\end{tabular} & \begin{tabular}{|l|}
0.874 \\
\end{tabular} & 0.271 & \begin{tabular}{|l|}
0.291 \\
\end{tabular} & \begin{tabular}{|l|}
0.303 \\
\end{tabular} & 0.014 & 0.020 & 0.022 \\
\hline 2FELWd & 0.997 & \begin{tabular}{|l|}
0.997 \\
\end{tabular} & \begin{tabular}{|l|}
0.999 \\
\end{tabular} & \begin{tabular}{|l|}
0.002 \\
\end{tabular} & 0.003 & \begin{tabular}{|l|}
0.003 \\
\end{tabular} & 0.864 & \begin{tabular}{|l|}
0.870 \\
\end{tabular} & \begin{tabular}{|l|}
0.887 \\
\end{tabular} & 0.269 & \begin{tabular}{|l|}
0.283 \\
\end{tabular} & 0.293 & 0.014 & 0.020 & 0.021 \\
\hline
\end{tabular}

Notes: FELW: Feasible Exact Local Whittle estimator, FELWd: Feasible Exact Local Whittle estimator with detrending, 2FELW: 2-Stage Feasible Exact Local Whittle estimator, 2FELWd: 2-Stage Feasible Exact Local Whittle estimator with detrending. Tests are conducted at 5 percent significance levels with $T=500$ critical values and simulations are carried out by assuming $v=T^{0.6}$. 
Table 3: Country pairs implying fast convergence and slow convergence.

\begin{tabular}{|c|c|}
\hline Top \%10 slow convergence pairs & Top \%10 fast convergence pairs \\
\hline $\begin{array}{l}\text { CR-CH, BE-ES, BE-CH, PK-SA, DK- } \\
\text { CH, EG-SE, AT-CH, PK-PE, EG-DE, } \\
\text { EG-LK, FR-HU, CR-DE, DE-IN, EG- } \\
\text { CH, AR-KR, HU-NL, EG-ES, EG-ID, } \\
\text { UY-US, LK-GB, EG-IN, EG-TH, EG- } \\
\text { MY, CR-ES, EG-GB, EG-FR, AT-FI, } \\
\text { EG-HU, BR-IS, CR-FI, EG-IR, EG- } \\
\text { FI, CO-ID, DK-FR, EG-PH, BE-FI, } \\
\text { AT-ES, EG-PT, GB-UY, EG-GR, CR- } \\
\text { KR, EG-NL, ES-CH, EG-PK, LK-TR, } \\
\text { GR-SA, SE-US, BE-KR, BE-TR, HK- } \\
\text { ZA, ES-TR, SG-GB, TR-GB, NO-SE, } \\
\text { DK-PE, FI-MX, FR-SG, IT-TT, CA- } \\
\text { FI, MY-US, DK-PK, KR-UY, EG-TR, } \\
\text { CA-VE, GR-NL, IS-SE, BE-PE, CO- } \\
\text { DE, CO-TH, EG-PE, CR-VE, CR-TR, } \\
\text { EG-VE, LK-VE, BE-VE, CR-PE, AT- } \\
\text { VE, NL-TT, GB-VE, EG-MX, PK-TH, } \\
\text { JP-ES, PK-ES, AT-TR, DK-VE, HU- } \\
\text { ES, TR-VE, ZA-CH, DK-TR, LK-UY, } \\
\text { MX-ZA, AT-PE, DE-KR, CR-EG, TT- } \\
\text { VE, PT-UY, TR-UY, SE-TR, CA-CO, } \\
\text { CL-CR, FI-IS, BE-PK, EG-IL, SG-ES, } \\
\text { NL-SE, DK-KR, HU-SA, NL-ZA. }\end{array}$ & $\begin{array}{l}\text { IT-LK, HU-UY, AR-UY, CN-TH, GR- } \\
\text { IT, CO-FI, HU-JP, IN-PT, DE-PH, } \\
\text { HK-PE, PT-SE, FI-MY, SE-GB, CN- } \\
\text { EG, CO-VE, BR-CO, SE-CH, NO-PT, } \\
\text { FR-MX, PH-SA, DE-IT, ID-PH, PT- } \\
\text { CH, FR-IL, ID-IL, CN-NO, PH-TT, } \\
\text { IT-NO, IT-PH, PE-US, IR-IT, DK- } \\
\text { HU, MY-TH, DE-ES, IT-ES, DK-GR, } \\
\text { IN-NL, CL-TH, MY-SG, IR-NO, CN- } \\
\text { ZA, CN-HK, PK-US, CR-UY, SG-US, } \\
\text { CN-GR, FR-ID, AT-EG, PE-UY, DE- } \\
\text { US, JP-SE, ES-LK, AT-CL, PH-ZA, } \\
\text { FI-GB, ES-TT, CA-TT, AT-UY, SA- } \\
\text { GB, MY-PH, ID-MY, CA-IL, NO-ES, } \\
\text { CL-EG, DE-IR, CA-KR, FR-GB, IN- } \\
\text { KR, SA-TR, KR-TR, BE-TT, PK-SE, } \\
\text { IN-PH, ES-VE, IR-PK, IR-TH, DE- } \\
\text { CH, ID-MX, CR-SA, IN-MX, BE-UY, } \\
\text { DK-SE, ID-JP, IR-TR, CL-SG, AT-SA, } \\
\text { ZA-LK, IR-PE, DE-MX, PH-SE, AT- } \\
\text { GR, PE-TH, PE-GB, PH-SG, CH-GB, } \\
\text { HU-LK, ID-PT, ID-PE, CL-NL, FI-ID, } \\
\text { CL-NO, AR-CN, NL-SA, IR-PT, CH- } \\
\text { TH, CA-IS, IT-JP, HU-PH. }\end{array}$ \\
\hline
\end{tabular}

Notes: Argentina (AR), Austria (AT), Belgium (BE), Brazil (BR), Canada (CA), Chile (CL), China (CN), Hong Kong (HK), Colombia (CO), Costa Rica (CR), Denmark (DK), Egypt (EG), Finland (FI), France (FR), Germany (DE), Greece (GR), Hungary (HU), India (IN), Indonesia (ID), Iran (IR), Ireland (IS), Israel (IL), Italy (IT), Japan (JP), Korea (KR), Malaysia (MY), Mexico (MX), Netherlands (NL), Norway (NO), Pakistan (PK), Peru (PE), Philippines (PH), Portugal (PT), Saudi Arabia (SA), Singapore (SG), South Africa (ZA), Spain (ES), Sri Lanka (LK), Sweden (SE), Switzerland (CH), Thailand (TH), Trinidad and Tobago (TT), Turkey (TR), United Kingdom (GB), Uruguay (UY), United States (US), Venezuela (VE). 
Table 4: Regression Results.

\begin{tabular}{|c|c|c|c|c|c|c|c|}
\hline \multicolumn{8}{|c|}{ ALL } \\
\hline & (Intercept) & DIS & LAN & $\mathrm{BOR}$ & TRADE & INF & EX \\
\hline Coefficients & 0.8592 & 0.0222 & 0.0103 & -0.0125 & 0.1146 & -0.0001 & -1.8260 \\
\hline$t-\mathrm{val}(\mathrm{HAC})$ & 23.0110 & 4.9100 & 0.7587 & -0.5769 & 1.6864 & -0.0541 & -7.6690 \\
\hline \multicolumn{8}{|c|}{ AMERICA } \\
\hline & (Intercept) & DIS & LAN & $\mathrm{BOR}$ & TRADE & INF & EX \\
\hline Coefficients & 0.7986 & 0.0323 & -0.0043 & 0.0033 & 0.1704 & 1.6180 & -3.3780 \\
\hline$t$-val (HAC) & 1.8992 & 0.6480 & -0.0910 & 0.0534 & 0.6502 & 1.2360 & -2.5790 \\
\hline \multicolumn{8}{|c|}{ ASIA } \\
\hline & (Intercept) & DIS & LAN & BOR & TRADE & INF & EX \\
\hline Coefficients & 0.4380 & 0.0646 & 0.0148 & -0.0215 & 0.1513 & 0.0028 & 0.4795 \\
\hline$t-\mathrm{val}(\mathrm{HAC})$ & 4.6480 & 5.5764 & 0.5728 & -0.5752 & 1.9616 & 1.7879 & 0.8731 \\
\hline \multicolumn{8}{|c|}{ EUROPE } \\
\hline & (Intercept) & DIS & LAN & BOR & TRADE & INF & EX \\
\hline Coefficients & 0.8610 & 0.0647 & -0.0421 & -0.0263 & 0.7548 & -1.4177 & -15.7670 \\
\hline$t-\mathrm{val}(\mathrm{HAC})$ & 5.7450 & 4.1223 & -0.9182 & -0.7463 & 3.7231 & -0.5036 & -2.8680 \\
\hline \multicolumn{8}{|c|}{ OTHER } \\
\hline & (Intercept) & $\overline{D I S}$ & LAN & $\mathrm{BOR}$ & TRADE & INF & EX \\
\hline Coefficients & 1.1350 & -0.0091 & 0.0231 & 0.0531 & 0.0894 & -0.0010 & -1.9720 \\
\hline$t-\mathrm{val}(\mathrm{HAC})$ & 13.5190 & -0.9337 & 1.3400 & 0.5218 & 0.6424 & -0.8033 & -7.4600 \\
\hline
\end{tabular}

Notes: $t$-values are computed from heteroskedasticity and autocorrelation consistent (HAC) variance-covariance matrices. ADD THE LIST OF COUNTRIES The group OTHER refers to cases in which trade partners belong to different geographical groups. 
Figure 1: Pesaran statistics for real exchange rates (monthly data)

(a) $D_{t}^{2}=\frac{2}{N(N-1)} \sum_{i=1}^{N-1} \sum_{j=i+1}^{N}\left(q_{i, t}-q_{j, t}\right)^{2}$, (b) $M D_{t}=\frac{2}{N(N-1)} \sum_{i=1}^{N-1} \sum_{j=i+1}^{N}\left|q_{i, t}-q_{j, t}\right|$.

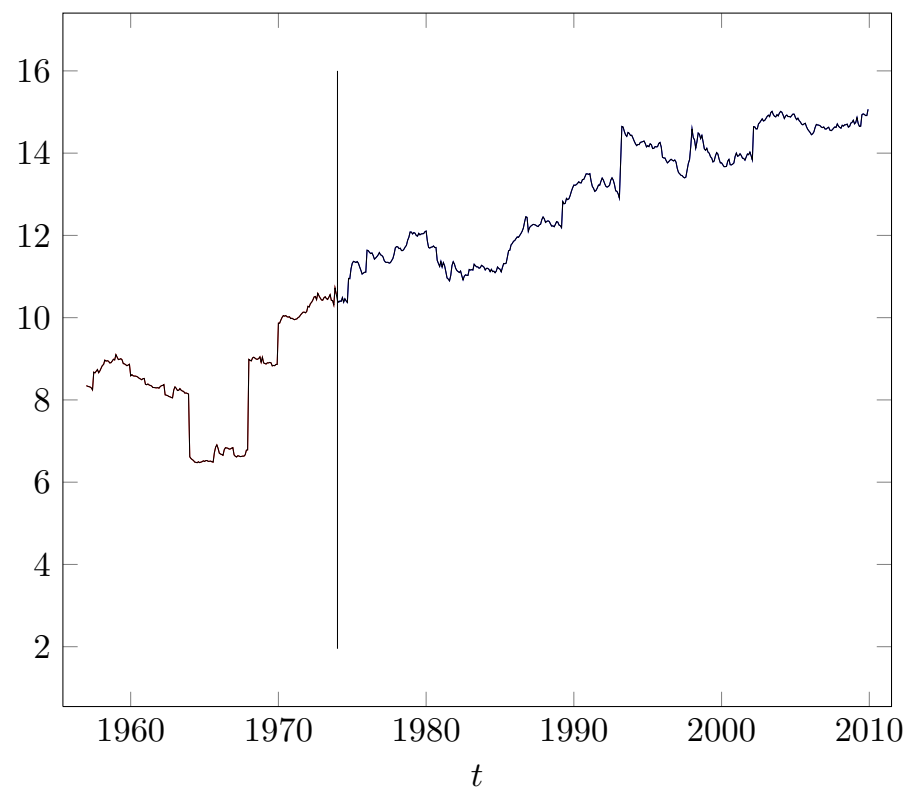

(a)

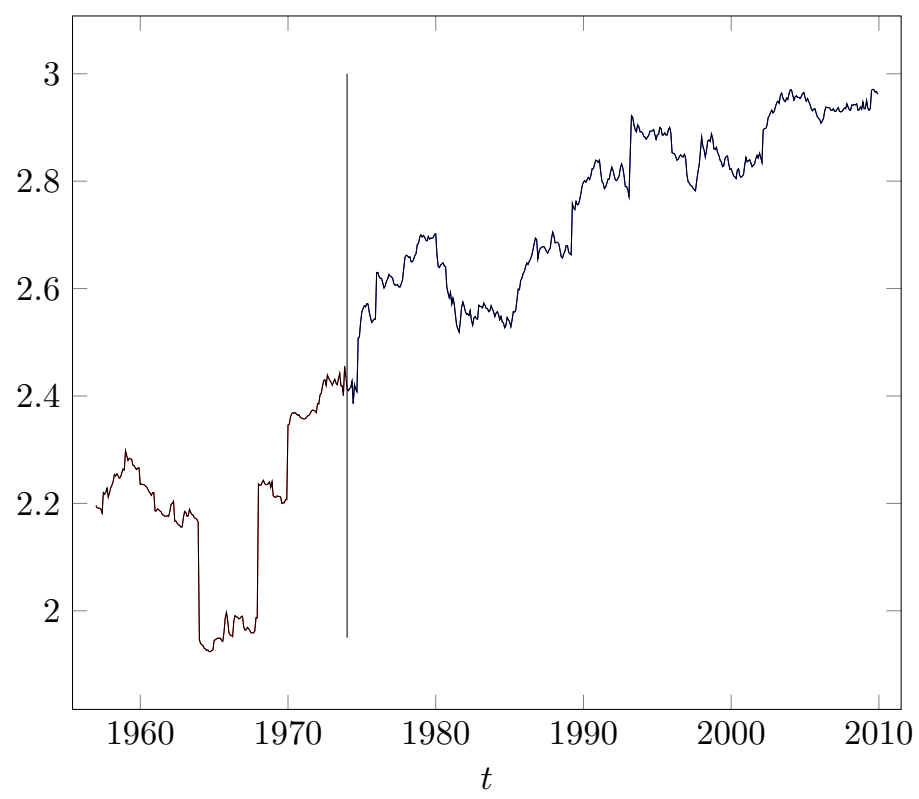

(b) 
Figure 2: Pesaran statistics for real exchange rates (quarterly data)

(a) $D_{t}^{2}=\frac{2}{N(N-1)} \sum_{i=1}^{N-1} \sum_{j=i+1}^{N}\left(q_{i, t}-q_{j, t}\right)^{2}$, (b) $M D_{t}=\frac{2}{N(N-1)} \sum_{i=1}^{N-1} \sum_{j=i+1}^{N}\left|q_{i, t}-q_{j, t}\right|$.

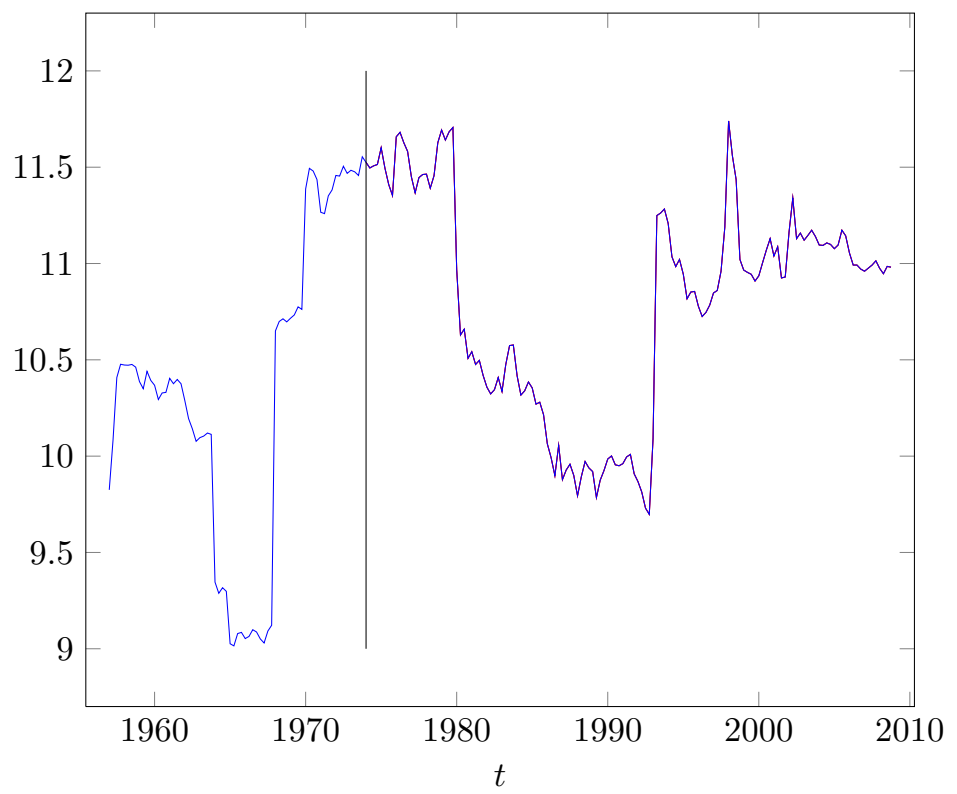

(a)

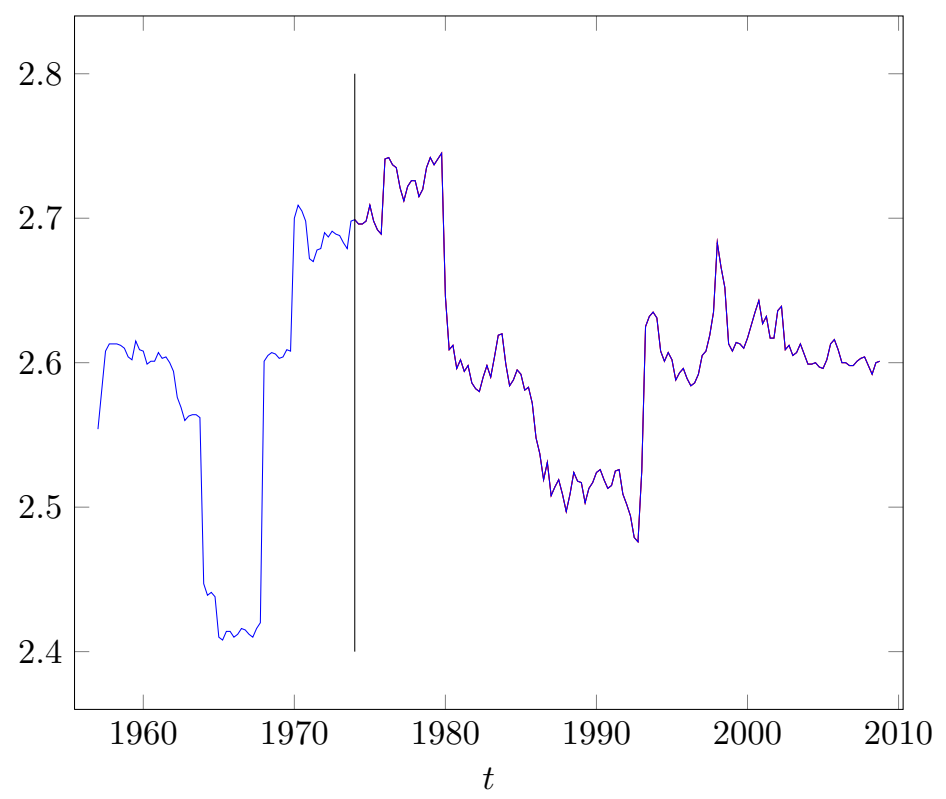

(b) 
Figure 3: Slow and low converging pairs with great circle lines on world map

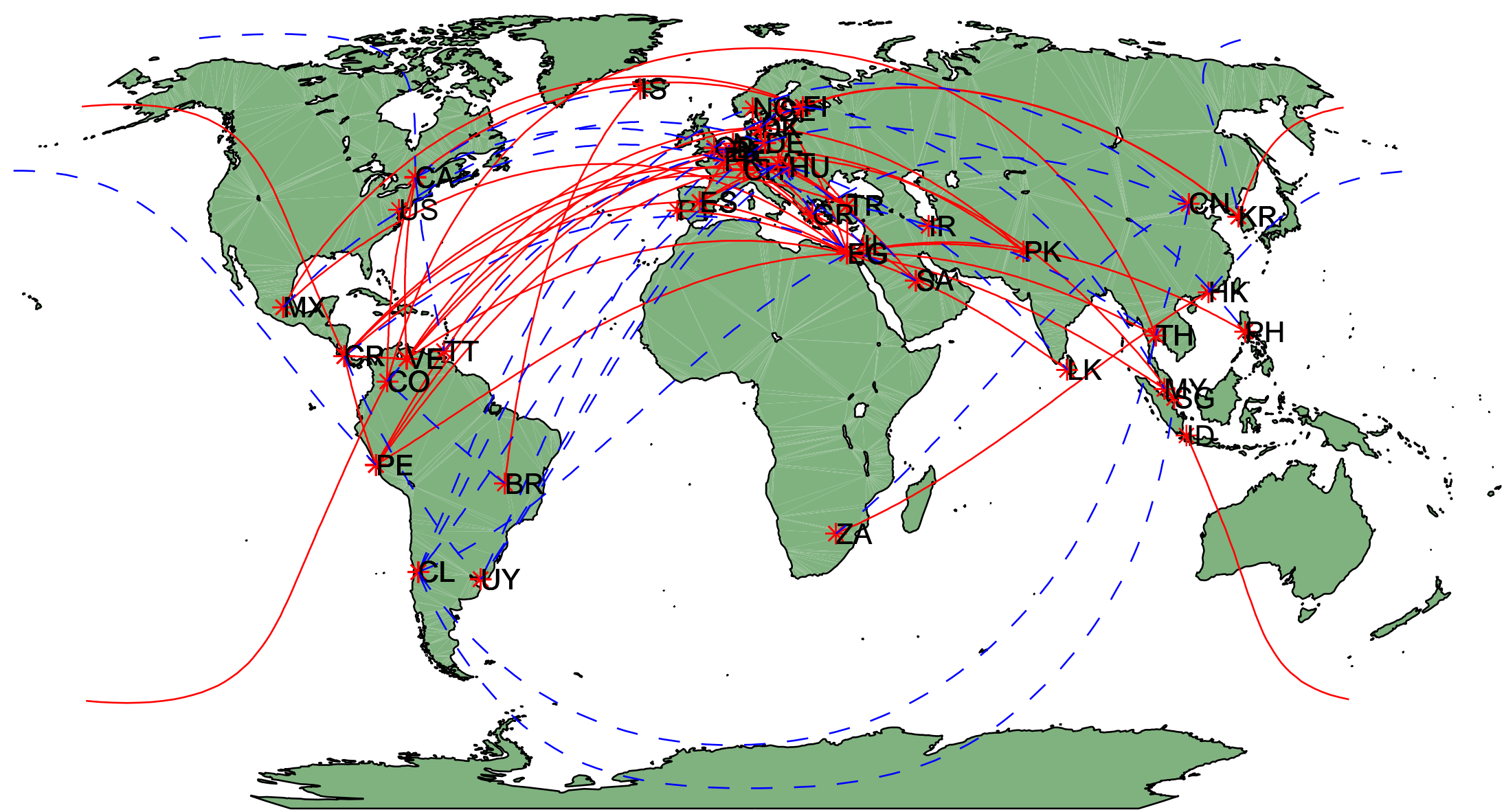

Note: The pairs connected with dashed lines and smooth lines are slow converging (high $d$ ) and fast converging (low $d$ ) ones, consecutively. 


\section{Appendix A}

Table A-1: Critical values of Test1-4, for $\mathrm{T}=100,200$, and 500.

(a) At $5 \%$ level of significance.

\begin{tabular}{|c|c|c|c|c|c|c|c|c|c|c|c|c|c|c|}
\hline & \multicolumn{3}{|c|}{ Test 1} & \multicolumn{3}{|c|}{ Test 2a } & \multicolumn{3}{|c|}{ Test 2b } & \multirow{2}{*}{\multicolumn{3}{|c|}{$\begin{array}{l}\text { Test } 3 \\
05 \%\end{array}$}} & \multicolumn{2}{|r|}{ Test 4} \\
\hline $\mathrm{CV}$ & & $95 \%$ & & & $05 \%$ & & & $95 \%$ & & & & & & $95 \%$ \\
\hline$\Gamma$ & 100 & 200 & 500 & 100 & 200 & 500 & 100 & 200 & 500 & 100 & 200 & 500 & 100 & 200 \\
\hline EW & 2.007 & 1.857 & 1.732 & 2.4 & -2.255 & -2.1 & 2.013 & 1.910 & 1.8 & 2.417 & -2.199 & -1.959 & 16 & 1.5251 .5 \\
\hline EL & & 1.989 & 1.8 & -2.3 & -2 & -2.1 & 2.180 & 1. & 1. & -2. & -2 . & -2 & 180 & 1.9761. \\
\hline & & 1.9 & 1.8 & & -2 & & 2.254 & 2.071 & 2.1 & -2. & -2 . & & 2.180 & 1.9741. \\
\hline & & & & & & & & & & & -2. & & 2.175 & 975 \\
\hline & - & & 1.8 & -2 & & & 2.2 & & & & & & 2.180 & 1.9741 .7 \\
\hline FELWd & & & & & & & & & & & & & 2.17 & 1.975 \\
\hline
\end{tabular}

(b) At $10 \%$ level of significance.

\begin{tabular}{|c|c|c|c|c|c|c|c|c|c|c|c|c|c|c|c|}
\hline & \multicolumn{3}{|c|}{ Test 1} & \multicolumn{3}{|c|}{ Test 2a } & \multicolumn{3}{|c|}{ Test $2 \mathrm{~b}$} & \multicolumn{3}{|c|}{ Test 3} & \multirow{2}{*}{\multicolumn{3}{|c|}{$\frac{\text { Test }}{90 \%}$}} \\
\hline $\mathrm{CV}$ & & $90 \%$ & & & $10 \%$ & & & $90 \%$ & & & $10 \%$ & & & & \\
\hline $\mathrm{T}$ & 100 & 200 & 500 & 100 & 200 & 500 & 100 & 200 & 500 & 100 & 200 & 500 & 100 & 200 & \\
\hline $\mathrm{EV}$ & 1.548 & 1.428 & 1.344 & -1.930 & 1.554 & 1.722 & 1.480 & -1.551 & 1.447 & .883 & 1.702 & 1.517 & 1.192 & 1.129 & 1 \\
\hline & & & & & & & & & & & & & & . & \\
\hline & & & & & & & & & & & & & & 64 & \\
\hline & & 1.305 & & & 1 & & 570 & & & & -1.705 & & 1.721 & 1.545 & 1 \\
\hline & 1. & 3 & 1. & & 1. & & 1.567 & -1 & 1. & & -1 . & & 1.725 & 1.546 & 1.413 \\
\hline FELWd & 1.435 & 1.305 & 1.200 & -2.413 & 1.590 & -2.103 & 1.391 & -1.854 & 1.266 & -1.881 & -1.705 & -1.579 & 1.721 & 1.545 & 1.412 \\
\hline
\end{tabular}

\section{Notes:}

Test 1: $H_{0}^{0}: d=0$ against $H_{1}^{0}: d>0$

Test 2a: $H_{0}^{1 / 2 a}: d=0.5$ against $H_{1}^{1 / 2 a}: d<0.5$

Test 2b: $H_{0}^{1 / 2 b}: d=0.5$ against $H_{1}^{1 / 2 b}: d>0.5$

Test 3: $H_{0}^{1}: d=1$ against $H_{1}^{1}: d<1$

Test 4: $H_{0}^{1}: d=1$ against $H_{1}^{1} \exp l: d>1$ 


\section{Appendix B}

\section{Data and sources}

Monthly data contains the data on following 47 countries: Argentina, Austria, Belgium, Brazil, Canada, Chile, China, HongKong, Colombia, CostaRica, Denmark, Egypt, Finland, France, Germany, Greece, Hungary, India, Indonesia, Iran, Ireland, Israel, Italy, Japan, Korea, Malaysia, Mexico, Netherlands, Norway, Pakistan, Peru, Philippines, Portugal, Saudi Arabia, Singapore, South Africa, Spain, Sri Lanka, Sweden, Switzerland, Thailand, Trinidad Tobago, Turkey, UK, US, Uruguay, Venezuela.

Quarterly data (1957Q1-2008Q4) belong to 42 countries. It excludes Colombia, Costa Rica, Egypt, Pakistan, Sri Lanka, Trinidad Tobago, Uruguay from the country set in monthly data, but also includes two new countries Australia (AU) and New Zealand (NZ). The variables used in the analysis are as follows:

Consumer price index $(P)$ : The data source for all counties was the IFS CPI (period averages). For China, 1986 M12 CPI value was taken from Dees et al. (2006), the remaining data were completed by using the growth rates of CPI published by IFS. For the period before German unification, in 1990M12, West German CPI (available up to 1991M12 in IFS) is used to obtain a common index.

Exchange rate $(E)$ : The data source for all counties was the IFS exchange rate (period averages). For the construction of euro area exchange rate each of the country members' exchange rate was converted to an index with 2000 as the base year using the euro conversion rate of the corresponding currency and the euro/dollar rate for that year.

Real exchange rate: Computed as $E P^{U S} / P$. All series are available between 1957M1 - 2009M12 except Argentina (1962M5-2009M12), Brazil (1996M1 2009M12), China (1986M12 - 2009M12), Costa Rica (1974M10 - 2009M12), Hong Kong (1980M10 - 2009M12), Denmark (1967M1 - 2009M12), Egypt (1957M1-2009M6), Hungary (1976M1 - 2009M12), India (1957M1-2009M11), Indonesia (1968M1-2009M12), Iran (1989M4 - 2009M12), Ireland (1997M1-2009M12), Korea (1970M1-2009M12), Peru (1960M1 - 2009M12), Saudia Arabia (1980M1-2009M12), Singapore (1961M1 - 2009M12), Thailand (1965M1-2009M12), Turkey (1969M1-2009M12) due to lack of data either in $E$ or $P$.

Trade Data: To construct trade data, IFS DOT (Direction of Trade) statistics were used. The exports and imports (c.i.f.) available at the annual frequency were downloaded for all the countries under consideration. The sum of imports of country 
$i$ from $j$ and exports of country $i$ to $j$, i.e. the trade flow of $i j$ country pair was calculated for each year for each country. Although, in principle, the trade flow data should be symmetrical in the sense that the trade flow of $i j$ country pair should be the identical irrespective of whether the data is reported by country $i$ or $j$, in practice a wide diversity exists among countries due to differences in definitions used and in methods of obtaining value information (see, Guide to DOT Statistics). Therefore, the trade data used in the above regression analysis were constructed as the time average of the following quantitities.

$$
\begin{aligned}
\operatorname{TRADE}_{i j, t} & =\frac{\text { Imports from } j \text { reported by } i+\text { Exports to } j \text { reported by } i}{\mathrm{GDP}_{i}} \\
& +\frac{\text { Imports from } i \text { reported by } j+\text { Exports to } i \text { reported by } j}{\mathrm{GDP}_{j}}
\end{aligned}
$$

Where all quantities are measured in terms of current US dollars. GDPs of the countries were obtained from IFS. 